\title{
Students' Engagement and Learning Process in Non-Language Focused MOOCs for EFL Purpose
}

\author{
Yuan Zhen \\ English dept. Shanghai Normal University Tianhua College \\ Shanghai, China \\ yuanzhen0317@163.com
}

\author{
Xiang Hongxing \\ Education dept. Shanghai Normal University \\ Tianhua College \\ Shanghai, China \\ hongxing33@126.com
}

\begin{abstract}
This study, under the theoretical framework of the Carroll model of school learning, aims to explore students' engagement and learning process in blended EFL context with non-language focused MOOCs as learning materials with ethnography study as the research method. 75 students were asked to participate in a three-month Coursera non-language course, besides originally planned lessons in college English class. Two of participants were purposefully selected for interview after completion of the online course, and their documents, assignments, projects, journals, chatting log were also collected for this qualitative research. The findings are positive: Certain non-EFL Coursera course is able to improve student's sense of English, and the experience can be considered useful supplement to training for English tests. Traditional teachers as well as MOOC providers may offer more instructions including time management, enhancement of willpower so that students will be more comfortable in getting used to the new paradigm.
\end{abstract}

Keywords-EFL, MOOC, Ethnography, Qualitative Research, Language Learning

\section{INTRODUCTION}

Massive open online course (MOOC) is currently one of the most popular words in the field of education; major platforms - Coursera, Udacity, edX, and Futurelearn, attracted well-known universities to establish courses. This innovation has a profound impact on the change of education paradigm, which has also been paid attention to by English as foreign language (EFL in short) teachers in higher education.

How to employ MOOCs for innovative EFL teaching is an important issue that needs to be answered. Many teachers continuously grope for blended English teaching mode, and have achieved a series of achievements. By participating in Coursera courses platform, the students' writing ability, speaking ability, and non-academic ability (interest in learning, metacognitive, self-efficacy) were significantly increased (Ma, Li\& Yan, 2014; Zhao, 2010)[5][6].

But this frontier paradigm, according to some educators, does not mean optimistic and sustainable development in the future. As for the effective lesson design, supervision methods in learning process, students' self-discipline and assessments, there is still not a mature practice model that can be used in EFL learning for higher education, especially the employment of online course which is not language focused. Meanwhile, the effectiveness of corresponding research is still a blank.
This study, under the theoretical framework of the Carroll model of school learning, aims to explore students' engagement and learning process in blended EFL context with non-language focused MOOCs as learning materials with ethnography study as the research method.

As for the theoretical framework for the study, we use Carroll model of learning, which holds that "the degree of learning or achievement is a function of the ratio of the time actually spent on learning to the time needed to learn”. It contains six aspects: aptitude, opportunity to learn, ability to understand instruction, quality of instructional events, perseverance and academic achievement.

Aptitude is defined as "the time a student needs to learn a given task ... to an acceptable criterion of mastery under optimal conditions of instruction and student motivation" (Carroll, 1989).[2]

Opportunity to Learn is "the amount of time available for learning”.

Ability to Understand Instruction includes language comprehension and learning skills. These are subject to development or enhancement if due time for learning is granted.

Quality of Instruction relates to such aspects of instruction as knowledge of objectives, access to content, and carefully planned and clearly specified teaching and learning.

Academic Achievement is measured by course grades, grade point average, achievement test scores, high school completion rates and college graduation rates.

Perseverance is measured by the amount of time a student is willing to spend on a learning task(Park, Y., Jung I., and Reeves, T.C, 2015)[4].

Their relation can be shown in Fig. 1 as follows 


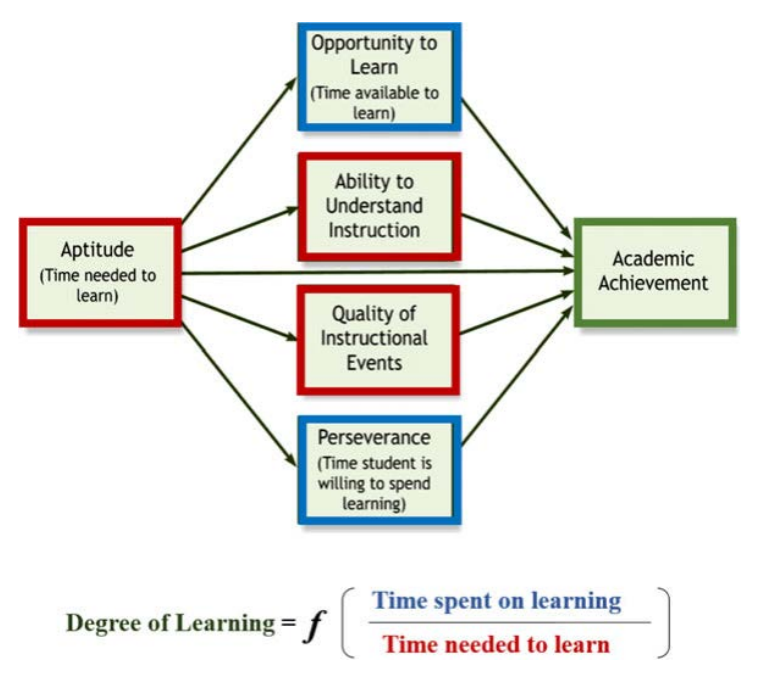

Fig. 1. Carroll’s (1963, 1989) model of school learning[1][2].

\section{Methodology}

In order to explore students' engagement and learning process in blended EFL context with MOOCs as learning materials, we decide to use ethnographic study as the research method. Creswell(2012)[3] defines ethnographic designs as "qualitative research procedures for describing, analyzing, and interpreting a culture-sharing groups' shared patterns of behavior, beliefs, and language that develop overtime.”

In our study, 75 students were asked to participate in a three-month long coursera online course-Design: creation of Artifacts in Society, besides originally planned lessons in college English class. Two of participants QZ and JH were purposefully selected for interview after completion of the online course, and their documents, assignments, projects, journals, chatting log were also collected for research.

\section{RESULTS AND DISCUSSIONS}

The results were analyzed in terms of input (one variable), process (four variables), and output(one variable).

\section{A. Input (Aptitude)}

Carroll regarded aptitude as the amount of time required to complete a task, assuming that as long as learners have adequate time and support, most of them will finally achieve goals in the syllabus.

The course of Design: creation of Artifacts in Society regulates that it lasts eight weeks long, five or ten hours each week. QZ reported emotional stress when she was one night before deadline for a certain weekly assignment, blank in her mind, knowing nothing about where to start. QZ said,

Almost every submit were just before the deadline, while fortunately some of the feedback were acceptable. Yet I don't like the feeling of being pushed by deadlines.

Not receiving any knowledge of time management, they two acknowledge problems on time allocation despite the opinion that it could have not been that nervous if they could have finished it earlier and left enough time for modification. Four or five hours per week isn't impossible to spare for fulltime students.

\section{B. Process}

\section{1) Opportunity to Learn}

Both of the interviewees reported constraint of time on campus, due to credit course assignments, club obligations, and personal arrangements. The Internet access is also a problem.

My daily schedule is busy. I'm running a student club of charity so I need to squeeze time out of the chaotic affairs. Besides, the Internet is quite slow in the dorm so oftentimes I finish it at home on weekends. It's faster and a quieter.

Four students share one bedroom in the dorm building, and all students, except the seniors are required to live on campus from Mondays to Fridays. The Internet on campus tend to be slower than home meanwhile the server of coursera located in US, which means the slower beaming speed and more patience when students are seated in front of the screen . Sometimes it feels frustrated to wait for the unfolding of the web page especially when it turns out to be a failure to be unapproachable.

\section{2) Ability to Understand Instruction}

Both of them reported language barrier. JH said,

They (professors) are native English speakers; the speed is very fast and I need to totally rely on subtitles. Even the subtitles are too difficult for me to understand. So I sometimes just to focus on the slides and the body language in the video really help.

If he is in a hurry, he might just skip those academic vocabularies, but was able to understand overall meaning of the lecture after discussing it with the roommates or on BBS, which is a surprise.

QZ also reported a problem about online learning distraction. A lot of materials have to be processed online, meanwhile distractions like system alert or popped ad windows can easily divert one's attention to a more interesting news page or Chat messengers

It works well for me sometimes to be completely off-line, and with pomodoro technique, I feel efficiency can be guaranteed while under other circumstances it's hard to maintain the willpower to keep myself away from those attractive entertainments

Self-discipline issues will be an important concern for online courses. Technical method hopefully can be helpful in handling distraction problem.

\section{3) Quality of Learning Design}

The course final project was a protocol of the creation. Each week's effort builds up the steps towards the final big one, which means sometimes when either they can't move on or a new idea came up, they have to start over. 
The assignment is so consistently designed that you cannot finish this weeks if you didn't do well last week, which is the foundation to this week and next week. It is like one chain after another.

The logical design of MOOC assignments, on the other hand, implies the inconsistency of assignments in the traditional classroom, which is note-worthy.

\section{4) Perseverance}

With different learners' identification of the purpose of participating MOOC, they varied in perseverance, the amount of time they were willing to give. QZ gives four hours each week while $\mathrm{JH}$ three. They both considered giving up at certain stages.

Motivation is also one big factor that influences one's perseverance. They are not motivated by extrinsic rewards like academic credit or professional certificate. Instead their curiosity about the new methods of EFL learning and eagerness to access to worldwide to learners and famous professors' teaching are the intrinsic motivation that drives them along the track.

What's more, peer support, accompany, even concerted complaints all contribute to strengthen the perseverance

\section{Output (Academic Achievement)}

They reported the gains of knowledge, either in language acquisition or profession development, as well as academic skills. It is considered a supplement to what teachers taught.

\footnotetext{
Materials are very authentic...much better than simulation listening practice for CET4. After watching videos again and again, I thought I could gradually follow the flow of the speaker and the reading experience is more fluent than before. It is also exciting to read assignments from students in other countries in English.
}

This reflection support positive impact of the experience on EFL learning outcome. With vivid videos and authentic reading materials, the input allows students' initiative engagement in EFL learning and don't have to directly face the pressure of CET4 training (short for College English Test Band 4, a national English test for college students, most schools require the grade of minimum 425 for a bachelor's degree).
As for academic skills, JH said,

Since professor in the video speaks to fast that I have to pause from time to time and take notes. Then note taking skills learned from Academic English class are practiced here. It is kind of to put what you learned into practice.

From mentioned above, traditional teachers as well as MOOC providers may offer more instructions including time management, willpower to set aside distraction, and better design of units and how to access faster Internet to improve students' learning experience in terms of EFL. Coursera course, under careful selection, is able to improve student's sense of English, and the experience can be considered useful supplement to placid training materials for tests.

\section{CONCLUSION}

In general, students are satisfied with experience through MOOC. Through Carroll's model of school learning, we analyzed students' engagement and learning process in blended EFL context with MOOCs as learning materials with ethnography study as the research method. While small student sample does not allow for generalization, their experience offers us insights to EFL teaching.

\section{REFERENCES}

[1] Carroll, J. B. “A model of school learning." The Teachers College Record, vol.64. pp.723-733,1963.

[2] Carroll, J. B. "The Carroll model: A 25-year retrospective and prospective view.” Educational Researcher, vol.18, pp. 26-31, 1989.

[3] Creswell, J. W. Educational research: Planning, conducting, and evaluating quantitative. Upper Saddle River, NJ: Prentice Hall, 2002.

[4] Park, Y., Jung I., and Reeves, T.C. "Learning from MOOCs: a qualitative case study from the learners' perspectives.” Educational Media International, vol.52.2 pp. 72-87, 2015.

[5] Ma, W.L., Li, Y. and Jiang, Y. "International MOOCs Teaching Design's Advantage and Problem - Take the example of English Composition I: Achieving Expertise from Duke University.” EEDUCATION RESEARCH, vol. 35.9, pp. 43-46, 2014.(In Chinese)

[6] Zhao, C.R. "Empirical study on fostering English autonomous study in online context—a case study based on A Guide to English-speaking Countries.” Continue Education Research, vol. 1, pp. 53-57, 2011.(In Chinese) 